\title{
In memoriam: Dr. Joseph Leung
}

\author{
Nicholas G. Hall ${ }^{1}$ Yumei Huo ${ }^{2} \cdot$ Benjamin $\mathrm{Li}^{3} \cdot$ Michael Pinedo $^{4} \cdot$ Hairong Zhao ${ }^{5}$
}

Published online: 20 October 2018

(c) Springer Science+Business Media, LLC, part of Springer Nature 2018

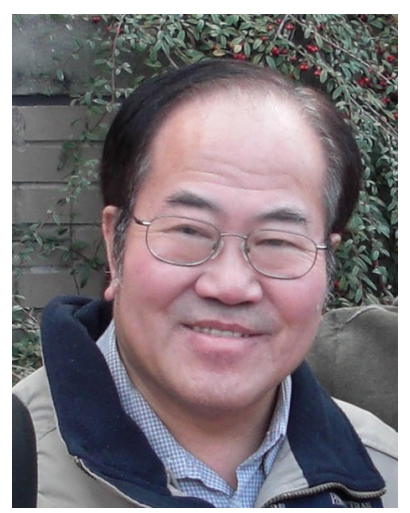

Dr. Joseph Leung, who was born in Hong Kong in June 1950, passed away in April 2018 due to complications of diabetes. Joe Leung was a Distinguished Professor at New Jersey Institute of Technology (NJIT), USA. He received his Bachelor of Arts in Mathematics from Southern Illinois University in 1972 and his Doctorate in Computer Science from Pennsylvania State University in 1977. In his dissertation research, Dr. Leung studied algorithms for packing problems under the supervision of Dr. Edward G. Coffman, Jr., a leading scholar in optimization and scheduling theory. Dr. Leung served as a faculty member at Virginia Tech, Northwestern University, University of Texas at Dallas, University of Nebraska and New Jersey Institute of Technology. From 1987 to 1990, he was an Associate Program Head at the University of Texas at Dallas. He also served as Department Chair at the University of Nebraska, from 1990 to 1996, and New Jersey Institute of Technology from 1999 to 2001.

$\triangle$ Michael Pinedo

mpinedo@stern.nyu.edu

1 Fisher College of Business, Ohio State University, Columbus, $\mathrm{OH}$, USA

2 The College of Staten Island, City University of New York, Staten Island, NY, USA

3 BNP Paribas, New Jersey, NJ, USA

4 Stern School of Business, New York University, New York, NY, USA

5 Purdue University Northwest, Hammond, IN, USA

Dr. Leung's contributions to the fields of theoretical computer science, scheduling theory, and combinatorial optimization are influential and extensive. He published 124 articles in highly regarded and competitive journals, including Operations Research, Mathematics of Operations Research, European Journal of Operational Research, Naval Research Logistics, SIAM Journal on Computing, Journal of Algorithms, and Journal of Scheduling. One of his most celebrated results concerns minimizing total tardiness on a single machine. The complexity of this problem had been studied for more than 30 years. In 1982, Lageweg, Lenstra, Rinnooy Kan, and Lawler offered a prize for resolving this problem. In 1990, Du and Leung published the paper "Minimizing Total Tardiness on One Machine is $N P$-hard" in Mathematics of Operations Research, showing the problem to be binary $N P$ hard and thus winning the prize. Another one of Dr. Leung's most highly cited papers is "On the Complexity of FixedPriority Scheduling of Periodic, Real-time Tasks" published in Performance Evaluation in 1982. The Earliest Deadline First algorithm analyzed in this paper is considered a classical CPU scheduling rule for many operating systems and is widely referenced in real-time systems textbooks.

In 2004, Dr. Leung edited the first handbook on scheduling: Handbook of Scheduling: Algorithms, Models, and Performance Analysis, published by CRC Press. This handbook provided a comprehensive coverage of the most recent and advanced topics on the subject. The handbook brought together 92 authors and co-authors from all over the world in management, industrial engineering, operations research, and computer science. It facilitated interdisciplinary collaboration, created new insights in scheduling, and promoted the critical role of scheduling in various important applications in modern society. Dr. Leung also co-edited the Handbook of Real-Time and Embedded Systems, which focused on real-time scheduling aspects of various modern embedded systems. This book integrated theory and practice and facilitated advancements in this area.

Dr. Leung received a diverse range of awards and recognitions including the 1981 Outstanding Young Men of America, American Men and Women of Science, Who's Who Among Asian Americans, Who's Who Among Amer- 
ica's Teachers, Directory of World Academic/Industrial Researchers, and the 2007 Excellence in Research Award from the College of Computing Sciences at NJIT.

Dr. Leung was the advisor for $27 \mathrm{Ph}$.D. students, including Jianzhong Du (1988) and Gilbert Young (1989). His Ph.D. students have risen to prominent careers, both in academia and industry, with those working in academia being continuously active in scheduling research and related fields. As an advisor, Dr. Leung showed profound judgement and care in guiding the work of his students. His passion and rigor made him a role model in the field. As with all effective and caring teachers, Dr. Leung was adept at imparting his vast knowledge to his students, while simultaneously encouraging them to explore on their own. He is also remembered for his modesty and his kindness toward other younger scholars. In school, Dr. Leung was highly respected by both students and colleagues, and at home he was a beloved father and husband.

Joseph Leung's passing is a loss not only to his family and friends, but also to the academic institutions where he worked, and the academic community with which he was associated. He will be greatly missed, but his influence and passion will continue. 